\title{
The Practice of the Training on Stress Tolerance Increase of Ukrainian Students in the Sphere of Legal Education
}

\author{
Tamara Latkovska ${ }^{1}$, Mikhail Sidor ${ }^{2}$, Tetiana Goloyadova ${ }^{3} \&$ Andrey Kalimbet $^{3}$ \\ ${ }^{1}$ Grand PhD in Juridical Sciences, Professor, Department of Administrative and Financial Law, Chernivtsi Institute of \\ Law of the National University, Odessa Academy of Law, Chernivtsi, Ukraine. \\ ${ }^{2} \mathrm{PhD}$ in Juridical Sciences, Associate Professor, Department of Administrative and Financial Law, National University, \\ Odessa Academy of Law, Odessa, Ukraine. \\ ${ }^{3} \mathrm{PhD}$ in Juridical Sciences, Associate Professor, Department of Administrative and Financial Law, National University, \\ Odessa Academy of Law, Odessa, Ukraine. \\ Correspondence: Tamara Latkovska, Grand PhD in Juridical Sciences, Professor, Department of Administrative and \\ Financial Law, Chernivtsi Institute of Law of the National University, Odessa Academy of Law, Chernivtsi, Ukraine. \\ E-mail: latkovska123@gmail.com
}

Received: July 17, 2019

Accepted: December 5, 2019

Online Published: December 23, 2019

doi:10.5430/ijhe.v8n8p16

URL: https://doi.org/10.5430/ijhe.v8n8p16

\begin{abstract}
The new national curriculum implementation in the sphere of higher education in Ukraine raises the need for using tests as the means of students' knowledge assessment. The authors have identified the connection both between the level of stress tolerance and between the level of test passing by means of using the correlated analysis, the Kolmogorov-Smirnov test and the T-Wilcoxon test. The level of stress tolerance has a serious impact upon the students' test result. The students show a higher efficiency level while passing the test after visiting the training on stress tolerance increase. It has been identified that the opportunity value as to how to focus the students' attention on the test is an important harbinger of the thesis that the education of Ukrainian students should be followed by the assessment of their psychological state. The authors have identified that the students' psychological architype has an impact upon the education efficiency giving both similar and best results according to the results from other cultures.
\end{abstract}

Keywords: education, law, testing, training, Ukraine

\section{Introduction}

Modern society is characterized by the common use of the informational technologies in all the activity spheres. The education sphere, which uses new methods of knowledge assessment under the influence of mass global communication, is not an exception. According to the assessment of students' test results as a main criterion for entering to magistracy, the study of students' anxiety problems is topical during the test pass. One of the reasons for the inconsistency of the inner independent test results, comparing to the students' knowledge level, is their fright for computer testing, which is different from a common exam pass as far as there is no student-teacher connection and it excludes the subjective teachers' marks.

The test institutionalization as a method of knowledge assessment in higher education is topical and accepted by scientists, teachers and by education sphere managers (Azevedo et al. 2019; Walker \& Handley, 2016). The implementation of new national education programs for bachelors of legal specialties means that the use of information and communication technologies as well as the use of tests, as a main knowledge assessment, is an obligatory part of legal education in Ukraine (Talebi \& Nejad, 2019).

Based on that the testing is full of multiple emotions, which have an impact upon the test results, it is considered to be important to achieve a certain optimal excitement level. When students are in such state, it contributes to achieving good results but if the excitement becomes a fever - the consequences are negative. The most important is the state which is characterized by attentiveness, seriousness, confidence and calm. That's why the teachers' task is to create good conditions in the education sphere, which is possible by means of using psychological techniques which will help to reveal the state of anxiety and to overcome it. It is proved that even competent students may not reveal their abilities, professionalism, knowledge and skills in an indefinite or extreme situation, especially if they are in an anxiety state 
(Spirchagova et al., 2017). As a result, the practical education system should include not only the creation of tests but also the creation of optimal socio-psychological conditions so that students will be able to pass their exams well.

The aim of this research is to study the ability of using the psychological training on stress tolerance increase while training students as to how to pass their exams well and to find out if it has an impact upon the effectiveness of Ukrainian students' progress. The article is based upon the data collected from 104 Ukrainian students. The results which should be told about in this article are new. The research questions are as follows:

(I) Do the results of the test, which is passed by students who study law, differ before the training and after it?

(II) Do boys and girls have the same level of stress tolerance and how it influences their progress?

This research studies the level of students' stress tolerance namely, the tolerance of the fourth-year students as well as its connection with knowledge while passing the test, which gives both similar and best results according to the results from other cultures.

There has been presented the less typical perspective, which focuses on the change of differences in the stress level distribution between the students of different genders. The results show that the training pass on stress tolerance increase has a serious impact upon the students' knowledge.

While assessing the implementation opportunity of the training on stress tolerance increase into the education process, there has been identified that the level of importance "after" is lower than 0,05 in comparison with the importance "before" because the amount of positive shifts has increased.

The literature review shows that there is a clear evidence of the students' level of stress having impact upon their education results and also upon the possible means of stress tolerance decrease. The students' understanding of their psychological states during the test and their ability to control them allows to increase the effectiveness of the education activity, to avoid many stressful situations, to soften their impact or to widen them with the least losses. The experimental training on stress tolerance increase was carried out to reason this position.

The data collection was preceded by the letter of consent with the information about training. The research purpose was provided during the tutorial verbally. It lasted for 1 hour and 20 minutes. Then, the students were briefed on some features of the extreme training pass.

The participants were the students of higher education facilities who study law. On the whole, 225 students were offered to participate and only 180 out of them did it. The losses were due to the absence of the letter of consent or due to the students' absence during the research. The participation was voluntary. Thus, the universe rate was within the confidence interval. The participants answered the blank anonymously. In addition, the mark namely, male - female was given for further gender researches of students' anxiety.

Before allowing students to pass the training, they had to identify the individual rate of personal and situational anxiety, the stress tolerance and the willed self-regulation one. The psychological testing was carried out according to the following methods: the anxiety in academic achievement situation (Alpert\&Haber, 1960); the Spielberger - Khanin's test of personal and reactive anxiety, the method for the diagnosis of students' education motivation (Badmayeva, 2004). According to the number of blank points, it was pointed out that they were close to maximum and that students had an opportunity to focus their attention on answers. Moreover, all the participants underwent the testing for the assessment of their knowledge. As a result, it appeared to be that 104 students out of 180 (40 boys and 64 girls) had an increased anxiety level. Thus, the training pass on stress tolerance increase as well as further participation in the experiment was offered only to 104 students.

In general, the training is related to the interactive technologies, which were spread and are practically used in higher education schools all over the world (Huang 2019; Staubitz et al. 2019). In fact, the interactive education is a kind of an active one as well as a kind of a pedagogical model, which is aimed at activation of creative students' abilities. The interactive education is not limited to the interaction with the education or information transmission but is directed at the values' change, the change of senses, at the change of action experience and also it contributes to the formation and development of students' personality (Ahadi \&Jacobs, 2017).

The training work, in terms of this research, is based on some approaches that are as follows:

The individual one which is aimed at the change in personality and which leads to self-consciousness and development. 
The social one which is aimed at studying the interpersonal relations in a group. During the group dynamics' process, there are perfected the communicative skills and the willed self-regulation ones, which contribute to the formation of stress tolerance at every lesson.

The first stage of the experiment was carried out two months before the winter session. The training on stress tolerance increase was carried out during this stage. The training consisted of two blocks that are as follows: the development of students' adequate self-esteem ( 2 lessons), the formation of self-confidence ( 2 lessons), the formation of stress tolerance (3 lessons) and the formation of constructive psychological mechanisms (3 lessons). The lesson takes place 1 time per week. The duration of the lesson is 120 minutes in every group according to the optional lessons schedule. Every student shares his or her feelings at the end of every lesson. Then, students passed the test on the following subjects: "Administrative law" and "Financial law" for their knowledge assessment.

The second stage was carried out 2 months before the summer session. During this stage, there was carried out the same training with the same methods as during the first stage. Tests on the specialties namely, "Administrative law" and "Financial law" for their knowledge assessment were also passed.

The teachers' interview showed that the testing for knowledge assessment touched the same disciplines as: "Administrative law" and "Financial law". As a result, it is possible to say that no accidents, which could have trigged doubts in reliability of students' answers, happened. The data was analyzed by the authors with the help of the SPSS statistics. Apart from the evaluation of standard descriptive measures, the normality check with the help of the Kolmogorov-Smirnov test and the distribution-free test for data comparison and the Wilcoxon singled-rank test were used.

The variable sum reliability results meaning the value of the data collected were analyzed. Table 1shows the data distribution normality with the help of the Kolmogorov-Smirnov test. The asymptotic value is lower than 0,05 that means that the distribution differs from a normal one and thus, it is needed to use the distribution-free test for data comparison.

Thus, the most plausible thesis is that which says that the use of the students' level of anxiety predetermines the students' test results. But at the same time, the methods of stress tolerance decrease should be effective.

\section{Materials and Methods}

\subsection{Data}

The questionnaire of this research was created for the collection of information about the students' stress tolerance before the training and after it. It consisted of the individual rate of personal and situational anxiety, the stress tolerance and the willed self-regulation levels. According to the number of blank points, it was pointed out that they were close to maximum and that the students had an opportunity to focus their attention on answers. The psychological testing was carried out according to the following methods: the anxiety in academic achievement situation (Alpert \& Haber, 1960); the Spielberger - Khanin's test of personal and reactive anxiety and the method for the diagnosis of students' education motivation (Badmayeva, 2004). According to the number of blank points, it was pointed out that they were close to maximum and that the students had an opportunity to focus their attention on answers. Moreover, the participants underwent the testing for the assessment of their knowledge. As a result, it appeared to be that 104 students out of 180 (40 boys and 64 girls) had an increased anxiety level. Thus, the training pass on stress tolerance increase and further participation in the experiment was offered only to104 students.

\subsection{Participants and the Collection of Data}

This experiment was carried out in two Ukrainian universities. The data collection was preceded by the letter of consent with the information about training. The purpose of the research was provided during the tutorial verbally. It lasted for 1 hour and 20 minutes. Then, the students were briefed on some features of the extreme training pass.

The participants were the students of higher education facilities who study law. On the whole, 225 students were offered to participate and 180 out of them did it. The losses were due to the absence of the letter of consent or due to the students' absence during the research. The participation was voluntary. Thus, the universe rate was within the confidence interval. The participants answered the blank anonymously. In addition, the mark namely, male - female was given for further gender researches of students' anxiety. The teachers' interview showed that the knowledge assessment test touched the same disciplines as: "Administrative law" and "Financial law". As a result, it is possible to say that no accidents, which could have trigged doubts in reliability of students' answers, happened. 


\subsection{Analysis}

The data was analyzed by the authors with the help of the SPSS statistics. Apart from the evaluation of standard descriptive measures, the normality check with the help of the Kolmogorov-Smirnov test, the distribution-free test for data comparison and the Wilcoxon singled-rank test were used.

\section{Results and Discussion}

The first stage of the experiment was carried out two months before the winter session. The training on stress tolerance increase was carried out during this stage. The training consisted of two blocks that are as follows: the development of students' adequate self-esteem ( 2 lessons), the formation of self-confidence ( 2 lessons), the formation of stress tolerance (3 lessons) and the formation of constructive psychological mechanisms ( 3 lessons). The lesson takes place 1 time per week. The duration of the lesson is 120 minutes in every group according to the optional lessons schedule. Every student shares his or her feelings at the end of every lesson. Then, the student passed the test on the following subjects: "Administrative law" and "Financial law" for their knowledge assessment.

The second stage was carried out 2 months before the summer session. During this stage, there was carried out the same training with the same methods as during the first stage. Tests on the specialties namely, "Administrative law" and "Financial law" for the assessment of their knowledge were also passed.

The variable sum reliability results meaning the value of the data collected were analyzed. Table 1shows the data distribution normality with the help of the Kolmogorov-Smirnov test. The asymptotic value is lower than 0,05 that means that the distribution differs from a normal one and thus, it is needed to use the distribution-free test for data comparison.

Table 1. The normality of data distribution with the help of Kolmogorov-Smirnov test

\begin{tabular}{ccccc}
\hline Rate & $\begin{array}{c}\text { Boys - the amount before } \\
\text { training }\end{array}$ & $\begin{array}{c}\text { Girls-the } \\
\text { amount before } \\
\text { training }\end{array}$ & $\begin{array}{c}\text { Boys-the } \\
\text { amount after } \\
\text { training }\end{array}$ & $\begin{array}{c}\text { Girls-the } \\
\text { amount after } \\
\text { training }\end{array}$ \\
\hline $\mathrm{N}$ & 40 & 64 & 40 & 64 \\
$\begin{array}{c}\text { Features of Average normal } \\
\text { distribution deviation }\end{array}$ & 2,6000 & 2,5313 & 2,8750 & 3,0625 \\
Extreme Absolute & 0,98189 & 0,90797 & 0,82236 & 0,85217 \\
difference & 0,208 & 0,221 & 0,260 & 0,268 \\
positive & 0,179 & 0,221 & 0,215 & 0,201 \\
negative & $-0,208$ & -197 & -260 & -268 \\
Criteria statistics & 208 & 0,221 & 260 & 268 \\
Asymptotic value & $0,000^{\mathrm{c}}$ & $0,000^{\mathrm{c}}$ & $0,000^{\mathrm{c}}$ & $0,000^{\mathrm{c}}$ \\
\hline
\end{tabular}

$\mathrm{a}-$ the distribution checked is normal

$\mathrm{b}$ - calculated from the data

$\mathrm{c}$ - value correction of Lilliefors

As far as the data distribution is not normal it is possible to use the Wilcoxon singled-rank test to compare the groupswith one another before and after the experiment. The results of the comparison are shown in Table 1. 
Table 2. The results of students' knowledge of different gender role before and after the experiment

\begin{tabular}{|c|c|c|c|}
\hline Rate & $N$ & Average rank & Sum of ranks \\
\hline Boys (the amount negative ranks & $0^{\mathrm{a}}$ & 0,00 & 0,00 \\
\hline \multicolumn{4}{|l|}{ after the experiment) } \\
\hline Positive ranks & $11^{\mathrm{b}}$ & 6,00 & 66,00 \\
\hline Boys (the amount before the experiment) & $29^{\mathrm{c}}$ & & \\
\hline $\begin{array}{c}\text { Girls (the amount after negative ranks } \\
\text { the experiment }\end{array}$ & $0^{\mathrm{d}}$ & 0,00 & 0,00 \\
\hline Positive ranks & $34^{\mathrm{e}}$ & 17,50 & 595,00 \\
\hline Girls (the amount before the experiment) & $30^{\mathrm{f}}$ & & \\
\hline The total amount & 64 & & \\
\hline
\end{tabular}

a - boys (the amount after the experiment) - boys (the amount before the experiment)

$\mathrm{b}$ - boys (the amount after the experiment) - boys (the amount before the experiment)

$\mathrm{c}$ - boys (the amount after the experiment) -boys (the amount before the experiment)

$\mathrm{d}$ - girls (the amount after the experiment)-girls (the amount before the experiment)

$\mathrm{e}$ - girls (the amount after the experiment) - girls (the amount before the experiment)

$\mathrm{f}$ - girls (the amount after the experiment) - girls (the amount before the experiment)

The Table 2 shows the amount of work shifts and the level of significance in every group. As far as the level of significance is lower than 0,05 it is possible to say that the meaning "After" differs from the one "Before" in a boys and girls group.

The Table 3 shows the results of students' knowledge rate before the training pass on stress tolerance increase and after it. Then, we can say that the meaning "After" differs from the one "Before" because the level of significance is lower than 0,05 . The meaning "After" increased in comparison with the one "Before" because the amount of positive shifts increased.

Table 3. The knowledge level of students before the training pass and after it

\begin{tabular}{cccc}
\hline Rate & $N$ & $\begin{array}{c}\text { Average } \\
\text { rank }\end{array}$ & $\begin{array}{c}\text { Sum of ranks } \\
\text { Positive ranks }\end{array}$ \\
\hline The sum (after negative ranks the experiment) & $0^{\mathrm{a}}$ &, 00 &, 00 \\
The amount Coincident ranks before & $45^{\mathrm{b}}$ & 23,00 & 1035 \\
The total amount the experiment & $59^{\mathrm{c}}$ & \\
& 104 & \\
\end{tabular}

$\mathrm{a}-$ the amount (after the experiment) $<$ the amount (before the experiment)

$\mathrm{b}-$ the amount (after the experiment) $>$ the amount (before the experiment)

$\mathrm{c}-$ the amount (after the experiment) $=$ the amount (before the experiment)

Table 4 . The distribution of results using the T-Wilcoxon test

\begin{tabular}{cc}
\hline The Wilcoxon criteria & $\begin{array}{c}\text { Theamount (Aftertheexperiment) } \\
\text { - the amount (Before the experiment) }\end{array}$ \\
\hline $\mathrm{Z}$ & $-6,708^{\mathrm{a}}$ \\
Asymptotic \\
significance \\
(2-sided)
\end{tabular}

$\mathrm{a}-$ based on the negative ranks 


\section{Discussion}

The study of students' anxiety and its elimination means have been the subject of research for a long time (Sharok, 2018; Schönfeld et al., 2019; Rith-Najarian et al. 2019). The psychological well-being, the choice of higher education facility and the social adaptation have a serious impact upon the education satisfaction in university, which testifies to the quality of higher education on the whole.

What concerns the computer testing as a stress factor, it is important to pay attention to this form of students' anxiety check. The students' anxiety during the test is caused by the nervousness about further education in magistracy as well as by the ability of further employment and professional self-realization on the whole.

Hence, the perception of test as a stress situation depends on the psychological characteristic such as: anxiety, stress tolerance, willed self-regulation, academic knowledge motivation and value orientation (Schönfeld et al., 2019).

On the whole, the students' anxiety factors can be attributed to as follows:

1. The problems of education sphere: the problems of knowledge, the need for study, the learning of great amount of teaching material fast, the inability to work with the test tasks, tough control and the regulation of education regime.

2. The problem of social character: while computer testing, the connection namely, computer-student is characterized by a clear duration, the absence of the right for mistake and correction and by the absence of ability to specify the question or its formulation, which often leads to wrong answers.

3. The problems of psychological character: the absences of support from the side of a teacher while test passing may make students feel unconfident, which increases anxiety. Moreover, the impact of personal features, the fear of failing to meet their hopes, the insufficient self-confidence and the inability to control their emotional state contribute to the increase of anxiety.

4. The problems of personal upbringing: temporary difficulties and the need to organize the testing time.

5. The problems of informational support: the insufficient information about the test passing rules as well as about the examinees' rights and duties.

The separate vector of this research was the difference between the anxiety level of boys and girls and the connection of gender roles with the level of their knowledge and anxiety. The differences in stress tolerance applying to students of different gender roles were studied by M.Pourrajab, M.Rabbani and S. Kasmaienezhadfard(2014). The authors came to conclusion that the main factors of stress among women are financial and academic ones, whereas the main factors among men are the problems of family, psychological and physical. It is interesting that the difference between the stress tolerance of students is caused by different physiological and neuropsychological ranks. Moreover, men and women react to stress differently both psychologically and biologically (Verma et al., 2014).

In terms of this research, it was found out that students of different genders and different knowledge rates as well as motivation level during the session period have different levels of anxiety. Hence, the lower the level of anxiety, the higher the level of stress tolerance is:

- $\quad$ girls are characterized by a higher emotional stress than boys;

- $\quad$ successful students are characterized by a higher exam stress than students with a lower level;

- boys and girls with a high level of anxiety as well as an average and a low level of knowledge typically have the absence of motivation, low self-esteem and self-doubt.

The consequence of a high anxiety level is the students' stress. F.M. Morales-Rodriguez and G.M. Perez-Marmol (2019), who as a result of the two-dimensional analysis found out that the total acceptance of self-efficiency is bound to the state of anxiety, came to the same conclusion. It can be explained by that the efficiency of students is connected with the academic scenario of the education environment. Bad knowledge occurs as a result of the ineffective management strategies and a low emotional intelligence. Based on the ranks obtained it is important to take measures to control the students' psychological state.

D. Saleh et al. (2018) found out how to decrease the students' stress with the help of the stress program. The program of self-help namely, "I control my stress" («Je gère mon stresse») was based on the cognitive-behavioral therapy and it allows to take a great number of students due to its short format and accessibility.

As a result of the research carried out, there was found out that one of the main reasons of stress is the long computer using. The means as to how to decrease the students' negative psychological states were chosen the following ones: the giving of information about the diet and regular sport trainings and the propaganda of regular rest. All these may be 
achieved with the help of psychologists or advisers, who should motivate students to sport and to deliver motivational lectures A.S. Negi, A.Khanna and R. Aggarwal (2019).

The aim of using the training on stress tolerance increase during the education was founded in this research. As the data testifies, the students' knowledge, especially of those who passed the training on stress tolerance increase, rises. That's why it is important to implement the psychological methods of students' personality.

\section{Conclusion}

The authors have identified that the level of stress tolerance has an impact on students' knowledge while test passing. The students show higher efficiency rate while passing the test after the training. It was found out that the opportunity value as to how to focus the students' attention on the test is a more important harbinger of the thesis that the education of Ukrainian student should be followed by the assessment of their psychological state. It was offered to change the curriculum in such a way that the implementation of training lessons will be considered.

Not only were the reasons for stress, while passing the test, examined but also there was studied a possible efficiency from using the training on stress tolerance increase. It is important that higher education facilities' administration will increase the purposeful activity in the sphere of stress research among students and find the ways as to how to decrease its level. The authors have identified the training pass on stress tolerance increase has a serious impact upon the students' knowledge. They show higher efficiency level while studying the law before the experiment and after it. However, some students do not have to pass the training as far as their level of stress tolerance is within the norms. The enabling of students to pass the training should be grounded on previous testing and also it should be the main reason for the need to implement the training work into higher law schools. The results of this research have the practical importance for consultations and development of curriculums on the specialty namely, "Law".

\section{References}

Ahadi, S. \& Jacobs, R.L. (2017). A review of the literature on structured on-the-job training and directions for future research. Human Resource Development Review, 16(4), 323-349. https://doi.org/10.1177/1534484317725945

Alpert, R. \& Haber, R.N. (1960). Anxiety in academic achievement situations. The Journal of Abnormal and Social Psychology, 61(2), 207-215. https://doi.org/10.1037/h0045464

Azevedo, J., Oliveira, E. \& Beites, P. (2019). Using Learning Analytics to evaluate the quality of multiple-choice questions. International Journal of Information and Learning Technology, 36(4), 322 -341. https://doi.org/10.1108/IJILT-02-2019-0023

Badmayeva, N.G. (2004). Vliyaniyemotivatsyonnogofactoranarazvitiyeumstvennykhsposobnostei. Ulan-Ude: Издательство: ВСГТУ, 2004. 280 с. ISBN 5-89230-193-1 (Isdatelstvo: VSGTU, 2004. 280 s. ISBN 5-89230-193-1)

Bellino, F., Sinatra, M., de Palo, V. \& Monacis, L. (2017). How self-regulatory modes and perceived stress affect academic performance. International Conference on Health and Health Psychology, 30, 228-235.(https://www.futureacademy.org.uk/files/images/upload/4cpsyc2017.pdf) https://doi.org/10.15405/epsbs.2017.05.4

Bergmann, C., Muth, T. \& Loerbroks, A. (2019). Medical students' perceptions of stress due to academic studies and its interrelationships with other domains of life: a qualitative study. Medical Education Online, 24(1), 160-175. (https://read.qxmd.com/read/31007152/medical-students-perceptions-of-stress-due-to-academic-studies-and-itsinterrelationships-with-other-domains-of-life-a-qualitative-study). https://doi.org/10.1080/10872981.2019.1603526

Huang,T-C. (2019). Do different learning styles make a difference when it comes to creativity? An empirical study.Computers in Human Behavior, 100, 252-257. https://doi.org/10.1016/j.chb.2018.10.003

Jin, Y., He, L., Kang, Y., Chen, Y., Lu, W., Ren, X., Song, X., Wang, L., Nie, Z., Guo, D. \& Yao, Y. (2014). Prevalence and risk factors of anxiety status among students aged 13-26 years. International Journal of clinical and experimental medicine, 7(11), 4420-4426. (http://www.ijcem.com/files/ijcem0002289.pdf)

Morales-Rodriguez, F.M. \& Perez-Marmol, J.M. (2019). The role of anxiety, coping strategies, and emotional intelligence on general perceived self-efficacy in university students. Frontiers in Psychology, 10, 1689-1694. https://doi.org/10.3389/fpsyg.2019.01689 
Negi, A.S., Khanna, A. \& Aggarwal, R. (2019). Psychological health, stressors and coping mechanism of engineering students. International Journal of Adolescence and Youth, 24(4), 511-520. https://doi.org/10.1080/02673843.2019.1570856

Pourrajab, M., Rabbani, M. \& Kasmaiene zhadfard, S. (2014). Different Effects of Stress on Male and Female Students. The Online Journal of Counseling and Education, 3(3), 31-39.

Rith-Najarian, L.R., Boustani, M.M. \& Chorpita, B.F. (2019). A systematic review of prevention programs targeting depression, anxiety, and stress in university students.Journal of Affective Disorders, 257, 568-584. https://doi.org/10.1016/j.jad.2019.06.035

Saleh, D.,Camart, N.,Sbeira, F. \& Romo, L. (2018). Can we learn to manage stress? A randomized controlled trial carried out on university students. PLoS ONE, 13(9), e0200997. https://doi.org/10.1371/journal.pone.0200997

Schönfeld, P., Brailovskaia, J., Chi Zhang, X. \& Margraf, J. (2019) Self-Efficacy as a mechanism linking daily stress to mental health in students: a three-wave cross-lagged study.Psychological Reports, 122(6), 2074-2095. https://doi.org/10.1177/0033294118787496

Sharok, V.V. (2018). Emotsyonalno-motivatsyonnye factory udovletvorennosti obucheniyem v vuze, Sibirskii psychologicheskii zhurnal, 69, 33-45. https://doi.org/10.17223/17267080/69/2

Spirchagova, T.A., Nasyrova, A.M., Vakhitova, D.K., Sadrieva, L.M. \& Brodskaya, T.A. (2017). Pedagogical management of university students' communication ability development. International Journal of Instruction, 10(3), 79-92. https://doi.org/10.12973/iji.2017.1036a

Staubitz, J.L.,Lloyd, B.P. \& Reed, D.D. (2019). Effects of self-control training for elementary students with emotional and behavioral disorders. Journalof Applied Behavior Analysis. URL: https://europepmc.org/abstract/med/31478218 https://doi.org/10.1002/jaba.634

Verma, R., Singh Balhara, Y.P. \& Gupta C.S. (2014). Gender differences in stress response: Role of developmental and biological determinants.Industrial Psychiatry journal, 20(1), 4-10.https://doi.org/10.4103/0972-6748.98407

Walker, R. \& Handley, Z. (2016). Designing for learner engagement with computer-based testing, Research in Learning Technology, 24, 1-15. https://doi.org/10.3402/rlt.v24.30083

Talebi, S., \& Nejad, P. I. (2019). Comparing the Descriptive Assessment in terms of Critical and Creative Thinking among the Sixth Grade Students in the Public and Private Schools. UCT Journal of Social Sciences and Humanities Research, 7(02), 6-14. 